\title{
Consciousness: Signs of Time
}

\section{Rommel BC*}

Graduate School and College Professor, Jose Rizal University, Philippines

*Corresponding author: Rommel B de la Cruz, PhD, EdD, Graduate School and

College Professor, Jose Rizal University, Philippines, Email:

\section{Short Communication}

Volume 3 Issue 6

Received Date: July 02, 2018

Published Date: August 14, 2018

rainman_bc_2011@hotmail.com

\section{Short Communication}

The awareness of time is the channel through which he can access his consciousness. Until man had been aware of what he had done was related or not related to what he would do, he could have not latched on to the idea of his conscious existence. According to some psychologists and sociologists, awareness of time makes man in full grasp of his consciousness and life.

Time, liken to a river current, could have been indistinguishable and elusive without man's use of signs. States, actions, and events are actually realization of time. Albert Einstein taught us today that time is relative. An event like an exploding star which is visible here on earth had actually occurred millions of years before the appearance of man. Other life forms perceive time much slower with varied perspectives than that of man. He actually has been aware of time because he lets it and makes it possible to be populated with signs. What is a sign? The great semiologist Charles Pierce defined a sign as "something which stands to somebody for something in some aspect or capacity."

How could the ancient man understand the meaning of the sudden appearance of a very bright luminary than the use of signs available to him? He gave meanings to this celestial event through associating one sign to another, a process that is endless once puts into motion. This process constitutes a narrative which thickens in layers and plots in the passing of time.

With the use of signs, time is objectified, exposed to further analysis and endless interpretation. Its relativity is forgotten. It has become real. It has become history. History is represented by signs which are continually a source of meanings to interpret and transform signmediated realities. C. K. Ogden and I. A. Richards, authors of the book "The Meaning of Meanings" pointed how signs induced mental processes, which are in turn realized by symbols [1]. Thus, signs are the processes and medium of thoughts. Jonathan Bignell, in his 1997 book "Media Semiotics: An Introduction" wrote "consciousness and experience are built out of language and the other sign systems circulating in society that have existed before we take them up and use them [2]."

Time is more than mental. It has turned into material. Each period of time in history is made sense of a dominant body of signs which has been handed down by the generations that came before. In his survey of "Signs and Symbols," Adrian Frutiger believes "a pictorial signs are becoming ever more indispensable for human communication [3]." This body of signs is reconstructed in order to meet certain needs unique to a particular period of time and to keep the power to those who learn it effectively and efficiently. Communication and information technology, mass media, and education have catalyzed and expedited the evolution of the use of the body of signs as well as the number of signs available.

In the $21^{\text {st }}$ century, the development of signs has been brought out as well as influenced by the progress made in communication and information technology. Earlier man had to rely on rock surface, animal hide, and papyrus to produce and preserve signs. He used them to interpret and examine how time materialized through actions, states, and events. When he talked or wrote about actions, states, and events, he actually talked or wrote about time. Talking or writing about time, he accesses his consciousness.

Astounding leap in progress was made in the mid1440 s with the invention of the printing press. The 


\section{Psychology \& Psychological Research International Journal}

publication "Analyzing media: Communication technologies as symbolic and cognitive systems" reported that from 1450 to 1500 about nine million books were put in circulation from several thousands. This resulted in the generation of more signs and the multi-layering of their meanings. Several signs produced narratives by themselves or with connection with others. For example, the word "man" was in the continual process of reconstitution of its meanings during this period. From its generic meaning to its humanistic, religious, Platonic, and Beaconian meanings to name a few, the word was semantically and discursively reconstituted.

The coming of radio and TV then Internet has virtually altered the nature of the body of signs that populates and governs the relationship between time and consciousness. In her book "Eloquence in an electronic age: The transformation of political speechmaking," Kathleen Jamieson comments on the digestion and reduction of complex issues into visual and aural narratives. The technologies have restructured and re-characterized the nature of body of signs, making it highly amorphous and malleable to the consciousness of the sign users. Relevant to this Jamieson remarked [4].

"When visual images can communicate meaning instantaneously to individuals of different languages and faiths around the world, the function of words changes. In such a world, words contextualize pictures and specify desirable or practical courses of ensuing action."

The modern communication and information technologies have restored the sources of information brought about by the face-to-face contexts of oral communication. However, they seem to have produced more. C. K. Ogden and I. A. Richards conceive of context as most of the time yielding a number of contradictory meanings. They elucidated that "when a context has affected us in the past the recurrence of merely a part of that context will cause us to react in the way in which we reacted before." A context is not free from the mediation of signs. It is actually constituted by signs. Thus, meanings could be easily caught up in the interconnected mesh of signs. This concept of interweaving of signs could be illustrated by the theoretical abstraction of hypertextuality. Hypertextuality is the digital linking of a document to other documents, images, websites, and any source of whatever form of information. A click accesses meanings encoded in other signs. Thus, time is opened up with a system of multi-layered and -linked of signs which produces meanings whose dominance depends on power and politics [5].

What is the implication of everything that has been discussed on learning?

Modernity has given rise to time which is frenetically mediated by signs. As expounded in this essay, time is realized by states, actions, and events. It is not something separated from them. They are time; how consciousness has become aware of them is mediated by signs. Learning has to cope with the challenge that signs have generated. This challenge results in a disembodied identity as well as fragmented consciousness for the learner. In learning, human consciousness is being tossed endlessly in time. It has no anchor. It sails to neither some beach nor some harbor. It currently drifts in the signs of time.

\section{References}

1. Ogden CK, Richards IA (2001) The Meaning of Meaning. Cambridge: Routledge.

2. Bignell J (2002) Media Semiotics: An Introduction. 2nd (Edn.), Manchester University Press, UK.

3. Frutiger A (1998) Signs and Symbols: Their Design and Meaning. UK: Ebury Publishing.

4. Jamieson KH (1995) Eloquence in an Electronic Age: The Transformation of Political Speechmaking. UK: Oxford University Press.

5. Chesebro J, Bertelsen D (1996) Analyzing Media Communication Technologies as Symbolic and Cognitive Systems. NY: The Guilford Press, pp: 228.

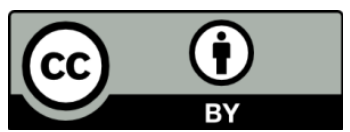

